\title{
Sea caged Atlantic salmon display size-dependent swimming depth
}

\author{
Ole FolKedAL ${ }^{\text {a }}$, Lars Helge STIEN, Jonatan NiLsSON, Thomas TORGERSEN, \\ Jan Erik FosSEIDENGEN and Frode OPPEDAL
}

Institute of Marine Research, 5984 Matredal, Norway

Received 18 January 2012; Accepted 24 April 2012

\begin{abstract}
The present study investigates vertical distribution of fish size in three $12 \mathrm{~m} \times 12 \mathrm{~m}$ wide and $14 \mathrm{~m}$ deep sea cages stocked with Atlantic salmon of average weight from 3.5 to $3.7 \mathrm{~kg}$, at commercial densities between 15.6 to $16.2 \mathrm{~kg} \mathrm{~m}^{-3}$, in Norway. For each cage, individual fish weight were estimated by three $0.6 \mathrm{~m} \times 0.6 \mathrm{~m}$ measuring frames as fish swam through. The frames were positioned at 3, 6 and $9 \mathrm{~m}$ depth. Recordings were carried out over five days per cage in succession, and during relatively stable environmental conditions in late autumn 2010. In all cages, measured fish were 15-25\% smaller at $3 \mathrm{~m}$ compared to the average weights at 6 and $9 \mathrm{~m}$ depth. Largest average weight difference between depths within one cage was $0.995 \mathrm{~kg}$. The average weight at 6 and $9 \mathrm{~m}$ was higher at night-time compared to daytime. Fish at the lower end of the weight spectrum were predominantly registered at $3 \mathrm{~m}$, while fish at the higher end of the spectrum were mostly registered at the greater depths. Fish of average size were well represented at all three depths. The fact that smaller fish swam shallower may be ascribed to natural behavioural traits and introduce an important consideration in representative sampling within commercial sea cages. In biomass estimations and sea lice counts size-dependent vertical stratification needs to be accounted for.
\end{abstract}

Keywords: Salmon-cage aquaculture / Fish behaviour / Vertical movements / Salmo salar

\section{Introduction}

During the on-growth phase in sea cages, Atlantic salmon (Salmo salar) are housed in groups of 10000 to 400000 individuals (Oppedal et al. 2011a), and display schooling behaviour (Fernö et al. 1988). Within these groups there is large variation in growth rate and size (e.g. Johansson et al. 2009). Shoaling fish tend to swim close to shoalmates of similar size (Hoare et al. 2000). Farmers claim that larger salmon swim deeper in the cage, and anecdotal observations of similar patterns have been made for other species (Sette 1950; Pitcher and Parish 1993), but such size stratification is yet to be documented. If size stratification does exist, this creates a possible bias when sampling of fish related to size and growth estimation, biomass calculations, veterinarian inspections and possibly measurements of sea lice abundance.

Information on the current fish biomass and size distribution in aquaculture salmon sea cages is important for the fish farmer. This in order to secure proper management and fish welfare related to stocking density and environmental conditions (Johansson et al. 2006, 2007, 2009; Oppedal et al. 2007, 2011a, 2011b), amount of food and pellet size, size sorting of fish, and to detect underlying causes of arrested growth. Also,

\footnotetext{
a Corresponding author: ole. folkedal@imr.no
}

this information is highly valuable for the farmer when preparing for slaughter and sale of the fish, when reporting to authorities and during control regimes by authorities.

The biomass can be estimated by using scientifically based growth curves where the number and average weight of delivered smolt, amount fed and temperature provides information to estimate biomass at any time during the course of the production. However, this estimate does not take into account underfeeding, waste-feed, seasonal effects, artificial light regimes, sexual maturation and unexpected levels of environmental factors that may alter the food conversion efficiency of the fish (e.g. Nordgarden et al. 2003). Thus, the accuracy of the above may have a high degree of uncertainty that increases with time. A commonly used supplementary method is to periodically sample a statistically relevant number of fish from each cage by using a casting net, normally in surface layers, and manually measure weight and length of these fish. An alternative is to use a biomass estimation frame. This is a square frame that is lowered into the cage. When fish swim through the frame light diodes create shadow pictures of the fish and automatic image analysis software estimate its size (Lekang 2007). Biomass estimation frames are readily available on the market, but depends in line with the use of casting net hauls that a representative sample of the cage group is sampled, i.e. swim through the measuring frame. 

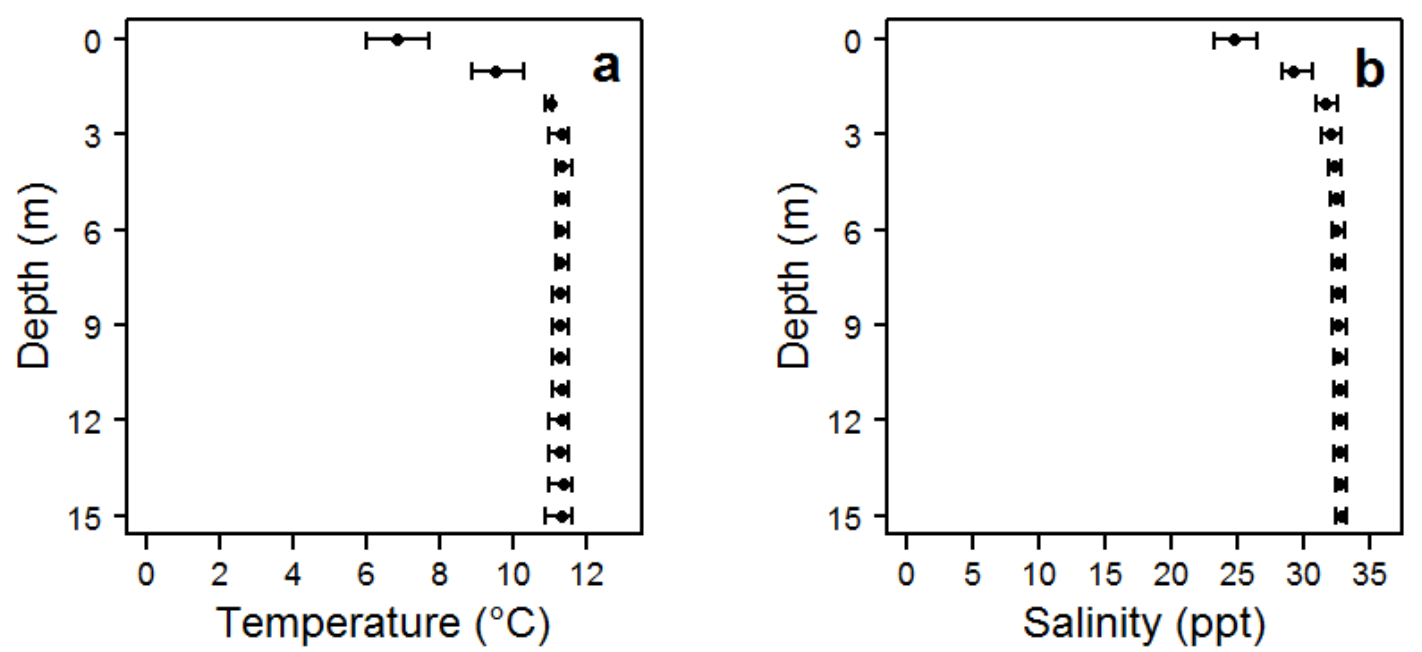

Fig. 1. Average temperature (a) and salinity (b) from surface to $15 \mathrm{~m}$ depth during the 17 days experimental period. Whiskers indicate the minimum and maximum registrations.

The aim of the current study was to investigate possible vertical size stratification in salmon sea cages, by measuring the size of individual fish recorded by size measuring frames at three different depths.

\section{Materials and methods}

\subsection{Location and experimental design}

The experiment was carried out between 18.11 and 4.12.2010 at Solheim cage laboratory $\left(61^{\circ} \mathrm{N}\right)$ of the Institute of Marine Research, Matre, Norway. Three square sea cages (12 $\mathrm{m} \times 12 \mathrm{~m}$ and $14 \mathrm{~m}$ depth; approximately $2000 \mathrm{~m}^{3}$ ) were used. In succession for the triplicate cages, three Vaki size measuring frames (Biomass Daily, Vaki, Iceland, www.vaki.is) were positioned at 3,6 and $9 \mathrm{~m}$ depth, respectively. The frames collected data for a minimum of five days within each replicate cage, where Day 1 of sampling in each cage started at midnight after the frames were positioned during the afternoon. The frames were positioned in the mid-radial horizontal plane, approximately $3 \mathrm{~m}$ from the net wall. The Vaki-frame is a $0.6 \mathrm{~m} \times 0.6 \mathrm{~m} \times 0.2 \mathrm{~m}$ (size of housing) frame with horizontal and vertical rows of IR-light diodes that construct shadow images and measures swimming speed of individual fish that swims through. This information is used to estimate the weight of individuals. By comparing weight data obtained from the biomass estimation frame with true fish weight, we found the deviation from true weight to be $-1.9 \pm 9.4 \%$ (mean $\pm \mathrm{SD}$, $n=19$ ), but the difference was not significant (paired $t$-test, $t=-0.72, p=0.48$, unpublished data), i.e. the average deviation is small.

\subsection{Environmental variables and feeding}

Depth profiles of water temperature and salinity were sampled daily with a vertically profiling CTD (SD204, SAIV AS,
Bergen, Norway, www.saivas.no) at a reference point outside the cages from surface to $15 \mathrm{~m}$ depth. The environment was stable during the experimental period, where the surface water layer was coldest and brackish, while both temperature and salinity were comparatively homogenous from $2 \mathrm{~m}$ depth to the cage bottom at $14 \mathrm{~m}$ (Fig. 1). The fish were fed a commercial diet (Skretting, Optiline 2050, $9 \mathrm{~mm}$ pellet size) in surplus, observed as waste feed below the population at the end of the meal, over two meals per day at 0900-1 130 and $1300-1500$.

\subsection{Experimental fish}

Atlantic salmon of the Aquagen strain where transferred to the sea cages in September 2009, and reared according to standard production routines. The fish were harvested between the 7th and 10th of January 2011, and counted to 9320, 8717 and 8680 individuals per cage with an average weight (gutted weight $+14 \%$ slaughter waste) of $4186 \pm 962$ (cage 1 , mean \pm SD), 4058 (cage 2, weight of individuals not available), and $4116 \pm 787 \mathrm{~g}$ (cage 3 ). Biomass during the experimental period was calculated by using the per cage mean harvest weight added estimated weight loss of $3.67 \%$ over the starvation period of 10 days before slaughter (Einen et al. 1998), and subtracted estimated growth since the experimental period using an SGR of $0.5 \%$ day $^{-1}$ (Austreng et al. 1987). This gave a biomass of 32510,31192 and $32270 \mathrm{~kg}$ and a stocking density of $16.26,15.60$, and $16.14 \mathrm{~kg} \mathrm{~m}^{-3}$ at Day 1 of recordings in cage 1,2 and 3 respectively.

\subsection{Vertical distribution in the cages}

Echo sounder data showed that the fish were spread out from top to bottom of the cage during the experimental period (Fig. 2). The vertical distribution of fish within cages was 

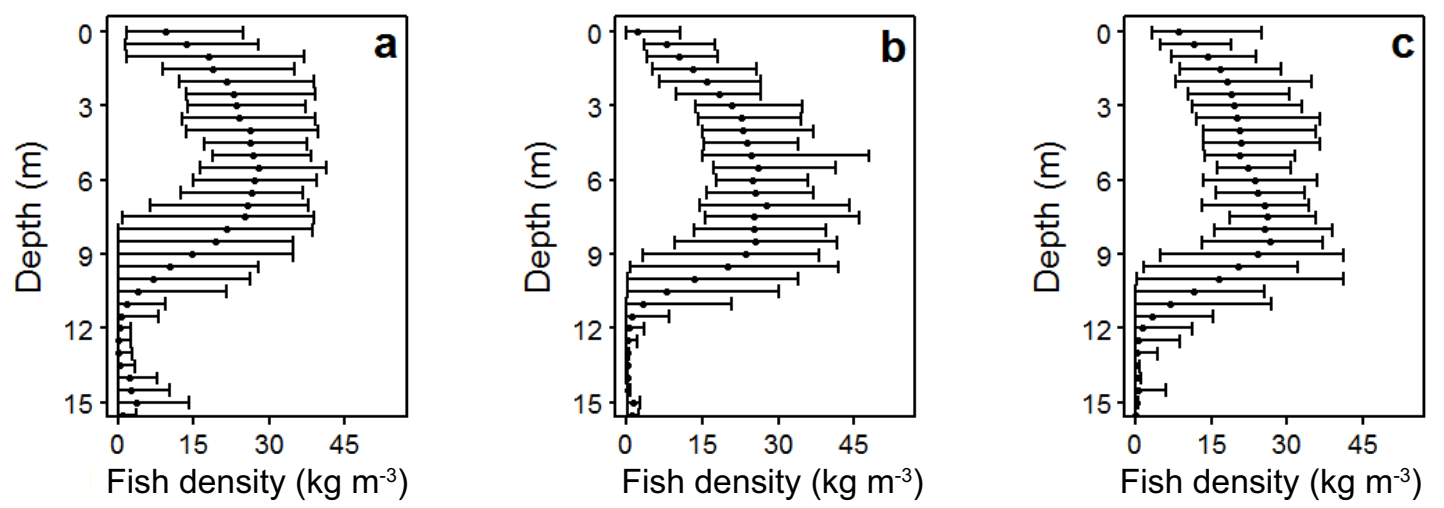

Fig. 2. Average observed fish density $\left(\mathrm{kg} \mathrm{m}^{-3}\right)$ by depth in sea caged Atlantic salmon, determined by echo-sounder over five days experimental period in each cage. Whiskers indicate the minimum and maximum observations. Stocking density is estimated to $16.3,15.6$, and $16.1 \mathrm{~kg} \mathrm{~m}^{-3}$ at Day one of sampling in cage 1 (a), 2 (b) and 3 (c) respectively.

observed continuously by a PC-based echo integration system connected to upward facing transducers with a $42^{\circ}$ acoustic beam angle. Transducers were positioned at approximately $17 \mathrm{~m}$ depth below the mid-point of each cage. Full details of the system are given in Bjordal et al. (1993) and review of its use in Oppedal et al. (2011a). Echo intensity, which is directly proportional to fish density, was recorded at $0.5 \mathrm{~m}$ depth intervals from $0.5 \mathrm{~m}$ to $15 \mathrm{~m}$ and converted to relative echo intensity (ER) in each of the 30 depth intervals.

Observed fish density (OFD) in $\mathrm{kg} \mathrm{m}^{-3}$ in each depth interval $i$ was calculated as $O F D_{i}=B E R_{i} V^{-1}$, where $B$ is total biomass in the cage, $E R_{i}$ is $E R$ of depth interval $i$ and $V$ is the volume of the $0.5 \mathrm{~m}$ depth interval $\left(72 \mathrm{~m}^{3}\right)$. A mean value of the echo observations per minute ( 60 pings $\mathrm{min}^{-1}$ ) was stored and condensed to hourly averages per depth interval prior to analysis.

\subsection{Statistical analyses}

The data were analysed with the R software system Version 2.9.0 (Copyright 2009, The R Foundation for Statistical Computing, Vienna, Austria). Time stamped data at minute level of individual fish measurements were retained in the Biomass Daily software system (Vaki, Iceland, www.vaki.is) and grouped according to cage and frame depth. Based on the time stamp the observations were classified as 'daytime' if they were between sunrise and sunset (between 08:49 and 16:00 at Day 1, and between 09:28 and 15:32 at Day 17), otherwise they were classified as 'night-time'. Data for the percentage frequency of observations, and proportions of small and large fish were arcsine transformed $\left(\sin ^{-1}(0.01 p)^{0.5}\right.$, where $p$ is the percentage value) to facilitate comparisons by two sided Welch $t$-test (Crawley 2007) (function $t$-test, R). Effects on measured mean weight from frame depth were investigated using mixed effects models (Crawley 2007), with frame depth as fixed effect and cage and frame depth as random effects (function lme, R). Similarly when investigating effects on mean weight from daytime per depth. The maximum significant level is set to $p=0.050$.

\section{Results}

\subsection{Frequency of registrations at daytime vs. night-time and at different depths}

Although daytime (light hours) only constituted about 7 hours of the total 24 hours day a clear majority $(64 \%$, $t=2.532, p=0.035, d f=8$ ) of the frame registrations occurred during light hours for all cages and frames. Within each triplicate cage, the frequency of registrations per frame was higher at $3 \mathrm{~m}$ depth $(62,39$ and $46 \%$ of the registrations for cage 1, 2 and 3, respectively) compared to 6 (17, 28 and $30 \%)$ and $9 \mathrm{~m}(21,34$ and 25\%) (Fig. 3).

\subsection{Average weight and weight distribution at different depths}

The mean fish weight was $3175 \mathrm{~g}$ at $3 \mathrm{~m}$ depth, with significantly larger fish at $6 \mathrm{~m}(3812 \mathrm{~g}, t=5.982, p=0.004$, $d f=4)$ and $9 \mathrm{~m}$ depth $(3890 \mathrm{~g}, t=6.720, p=0.003, d f=4)$ (Fig. 3). There was no statistical difference between 6 and $9 \mathrm{~m}$ depth (3812 vs. $3890 \mathrm{~g}, t=0.808, p=0.504, d f=2)$. Within the single cages, the most remarkable between depth difference was recorded between 3 and $6 \mathrm{~m}$ in cage 3 (995 g), while in cage 1 and 2 the maximum differences was found between 3 and $9 \mathrm{~m} \mathrm{(673} \mathrm{and} 594 \mathrm{~g}$ respectively, see Fig. 3 and Table 1 for more details). The mean fish weight registered was smaller during daytime compared to night-time at $9 \mathrm{~m}$ depth (3 $764 \mathrm{vs}$. $4092 \mathrm{~g}, t=4.302, p=0.050, d f=2)$, less pronounced at $6 \mathrm{~m}$ depth (3710 vs. $3971 \mathrm{~g}, t=2.474, p=0.123, d f=2)$, while no effect from daytime was registered at $3 \mathrm{~m}$ depth (3 $190 \mathrm{vs}$. $3146 \mathrm{~g}, t=-1.044, p=0.406, d f=2$ ) (Table 1).

The weight distributions at all depths and cages were normal, and within each cage the majority of the observations per depth overlapped each other (Fig. 3). Accordingly, average sized fish were well represented at all depths. In order to distinguish between small and large fish (cf. Pitcher et al. 1985) we defined small and large fish as respectively smaller and larger than 1.5 standard deviations from the mean weight for each cage. In all three cages about $5 \%$ of the registrations at $3 \mathrm{~m}$ 

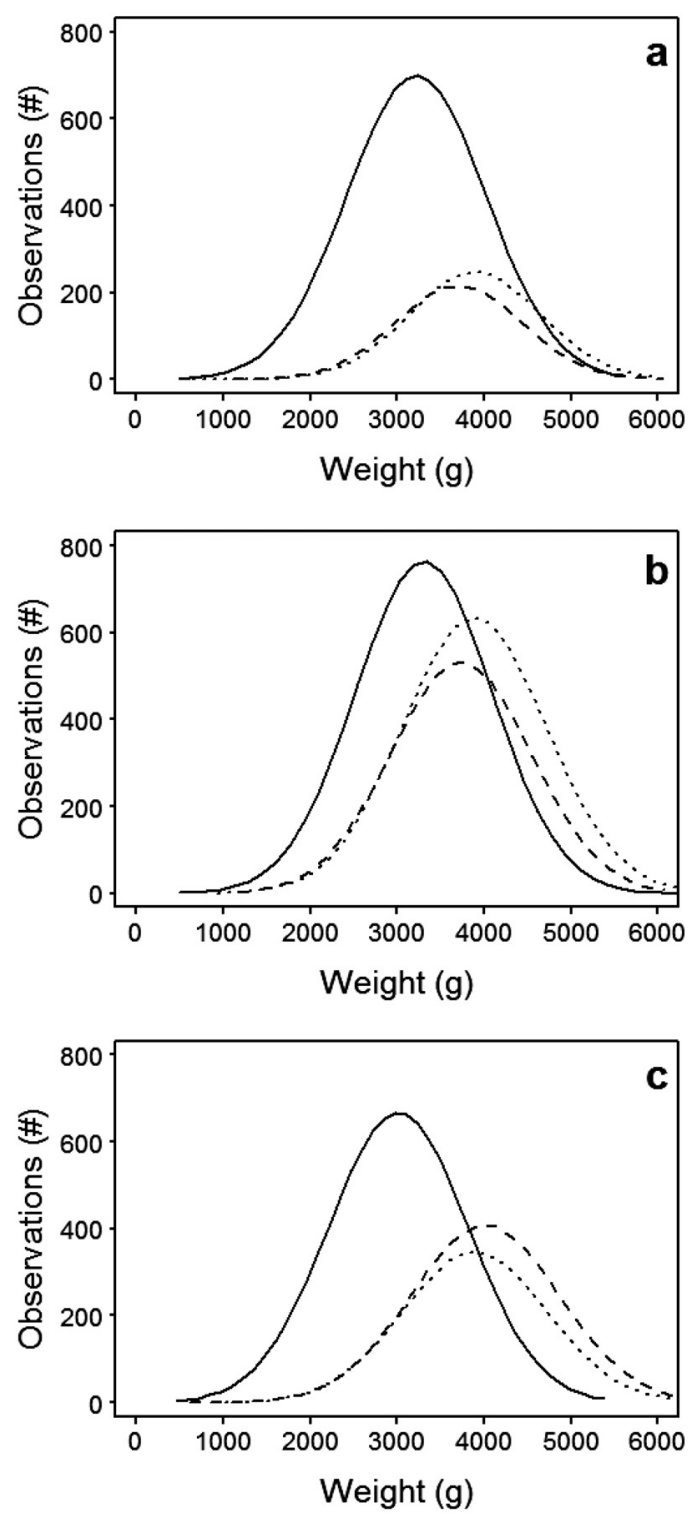

Fig. 3. Recorded weight distributions for Atlantic salmon in sea cage 1 (a), 2 (b) and 3 (c) at three different depths (3, 6 and $9 \mathrm{~m}$ ) measured by size measuring frames. Solid lines indicate $3 \mathrm{~m}$ depth, dashed line $6 \mathrm{~m}$ depth and dotted line $9 \mathrm{~m}$ depth. The lines are fitted on histograms of $100 \mathrm{~g}$ increment (function seq, R).

depth were small fish, while small fish constituted less than $1 \%$ of the registrations at 6 and $9 \mathrm{~m}(t=9.748, p<0.001$, $d f=6.970$ ) (Table 2, Fig. 3). Opposite, in all three cages between 2 to $5 \%$ of the registration at 6 and $9 \mathrm{~m}$ were large fish, while near $0 \%$ of the registration at $3 \mathrm{~m}$ were large fish $(t=5.393, p=0.009, d f=3.417)$ (Table 2, Fig. 3).

\section{Discussion}

\subsection{Size stratification}

Clearly, the observations confirm the assumption that caged Atlantic salmon display vertical size-stratification, with
Table 1. Mean values for the specific cages and measuring frame depths. Mean \pm SE body weight from individual measurements of fish weight by the measuring frames during daytime, night-time and combined.

\begin{tabular}{cclll}
\hline $\begin{array}{c}\text { Frame } \\
\text { position }\end{array}$ & Time of day & Cage 1 & Cage 2 & Cage 3 \\
\hline \multirow{3}{*}{$3 \mathrm{~m}$} & Daytime & $3246 \pm 8$ & $3299 \pm 6$ & $3023 \pm 7$ \\
& Night-time & $3146 \pm 12$ & $3345 \pm 33$ & $2961 \pm 14$ \\
& Combined & $3216 \pm 7$ & $3301 \pm 6$ & $3008 \pm 7$ \\
\hline \multirow{3}{*}{$6 \mathrm{~m}$} & Daytime & $3684 \pm 13$ & $3560 \pm 11$ & $3887 \pm 10$ \\
& Night-time & $3736 \pm 21$ & $3888 \pm 11$ & $4286 \pm 17$ \\
& Combined & $3701 \pm 12$ & $3729 \pm 8$ & $4005 \pm 9$ \\
\hline \multirow{3}{*}{$9 \mathrm{~m}$} & Daytime & $3828 \pm 13$ & $3773 \pm 8$ & $3690 \pm 14$ \\
& Night-time & $4000 \pm 19$ & $4218 \pm 14$ & $4056 \pm 13$ \\
& Combined & $3889 \pm 11$ & $3895 \pm 7$ & $3887 \pm 10$ \\
\hline
\end{tabular}

Table 2. Percentage of registrations classified as small/large fish for each measuring frame positioned at 3,6 and $9 \mathrm{~m}$ depth within each sea cage 1,2 and 3 .

\begin{tabular}{cccc}
\hline & \multicolumn{3}{c}{ Cage } \\
\cline { 2 - 4 } & 1 & 2 & 3 \\
\hline $3 \mathrm{~m}$ & $4.4 / 0.5$ & $4.8 / 0.4$ & $5.6 / 0.0$ \\
$6 \mathrm{~m}$ & $0.9 / 2.3$ & $1.8 / 2.5$ & $0.3 / 4.6$ \\
$9 \mathrm{~m}$ & $0.4 / 5.0$ & $0.9 / 4.5$ & $0.5 / 2.8$ \\
\hline
\end{tabular}

the smallest fish at the top of the school and the largest individuals near the bottom of the school. The overlaps in weight distribution for the different depths do, however, indicate that fish of average weight was well represented at all the recorded depths.

Previous scientific evidence of size stratification within single schools or shoals has mainly been based on studies of small group sizes and at a detailed level by the size of neighbouring individuals (e.g. Picher et al. 1985; Theodorakis 1989). Size stratification has been related to competitive ability, predation risk, hunger status and swimming speed (Hoare et al. 2000), and swimming with fish of similar size seems to be an active choice that may give hydrodynamic advantages in travelling groups (Pitcher et al. 1985). Relating to spatial distribution, Theodorakis (1989) found that the smaller fish in schools of different minnow species occupied the peripheral zone of the school, and Krause (1994) found the same for shoaling juvenile chub (Leucisus cephalus) when alarmed with Schreckstoff. By the use of measuring frames we were able to demonstrate size stratification at a much larger scale, although in less detail, and the current design only included the vertical dimension. Potential horizontal size stratification was, however, partially controlled for by the use of the same radial positioning of the frames at all three depths.

Salmon as a physostomous fish inflates its swimbladder at the surface and is unable to maintain swimbladder volume at the higher hydrostatic pressures at subsurface depths. The whole fish density therefore increases with depth. We hypothesize that the negative buoyancy salmon experience at larger depths constrains their distribution. Size and lipid content are strongly correlated, with a lipid content around $12 \%$ for $1.5 \mathrm{~kg}$ fish to about $18 \%$ for $4 \mathrm{~kg}$ fish (Solberg et al. 2003). The lower density of lipids of leaner fish implies that they are 
less buoyant than fatter fish, and should therefore be more restricted to shallow depths. It is therefore possible that the relationship between salmon density and size may be part of the explanation for the observed relationship between swimming depth and size. Our observation of higher average weight at night-time compared to daytime at both 6 and $9 \mathrm{~m}$ depth is in support of this. Negatively buoyant salmon behaviorally counter by increased swimming speed to generate hydrodynamic lift (Dempster et al. 2008, 2009; Korsøen et al. 2009), and at night-time, caged Atlantic salmon reduce their swimming speed and normally ascend towards the surface (Fernö et al. 1995; Oppedal et al. 2001; Korsøen et al. 2009). Slower swimming speed during darkness may thus constrain their vertical distribution with regards to maintaining buoyancy.

Emaciated and moribund fish are commonly found at the surface in salmon sea cages (e.g. Stephen and Ribble 1995), and should normally contribute to some size segregation. It is not likely that such individuals would be registered in the measure frames, considering their low abundance, very shallow swimming depth and low activity level.

\subsection{Water temperature and salinity}

Within the homogenous temperature and salinity layer the salmon distributed themselves relatively evenly with depth, and most of the fish avoided the cold and brackish surface water above the frame positioned at $3 \mathrm{~m}$ depth. Water temperature has been noted as a highly potent driver of salmon swimming depth in vertically stratified water, while salinity in this aspect is regarded as a less important variable (e.g. Oppedal et al. 2001, 2007, 2011a, 2011b; Johansson et al. 2006, 2009). Accordingly, the comparatively homogenous temperature at the recorded depths rules out temperature dependent size stratification.

\subsection{Competition and feeding}

Some environmental factors are unmeasured. Scramble competition for limited environmental resources is likely to occur in salmon sea cages (Johansson et al. 2006, 2007, 2009; Oppedal et al. 2011b) and we cannot exclude that such competition or preferences for environmental variables as oxygen or light levels, or water current velocity influence the size distribution. Competition for favourable positions within fish schools have been shown in relation to predator attacks (Pitcher and Parish 1993), where positioning with fish of similar size is regarded as a favourable strategy (Theodorakis 1989; Krause 1994). Larger individuals are generally more competitive, and will easier gain access to resources such as food (Krause 1994). For farmed Atlantic salmon reared at commercial stocking densities in aquaculture tanks, growth is negatively correlated with brain relative concentrations of serotonin, which is enhanced by reduced food availability (Cubitt et al. 2008). This is suggested to reflect social hierarchies (Cubitt et al. 2008). Whether social dominance among salmon exists in large groups in sea cages is, however, not known, but could be a potential source of size stratification.
The smaller fish positioned themselves closest to the surface feeding area. With regards to swimming depth, subgroups within the same sea cage are commonly observed, and may be explained by different hunger levels or unsynchronized feeding rhythms (Juell and Westerberg 1993; Juell et al. 1994; Juell 1995; Fernö et al. 1995). A positive correlation between hunger level and surface attraction has been showed at group level for caged salmon (Juell et al. 1994), and could be a likely cause of small and thus potentially hungrier fish to maintain position close to surface.

The observed diurnal difference of higher average weight at night-time compared to daytime at 6 and $9 \mathrm{~m}$ may be ascribed to feeding activity during the relatively long feeding periods that stretched over most hours of daylight. If not already present in the surface feeding area, caged salmon normally ascend towards the surface during feeding periods (Juell et al. 1994; Ang and Petrell 1998). Hence, one could expect a more homogenous size composition at $3 \mathrm{~m}$ during the hours of daylight. Such was not observed by the measuring frame, and may be explained by the heavy fish eating at greater depths, or simply that a lack of registrations of heavy fish at $3 \mathrm{~m}$ was due to individuals showing feeding behaviour not swimming through the frame as when schooling. Typically, feeding fish change from normal schooling and swim towards pellets in a more directed pattern (Juell and Westerberg 1993; Ang and Petrell 1998).

\subsection{Registration frequency with depth}

The number of observations varied both between the different cages and between the measuring frames in each cage, where cage 1 had considerably less observations at 6 and $9 \mathrm{~m}$ depth than at $3 \mathrm{~m}$, despite similar densities of fish at 3 and $6 \mathrm{~m}$. Less registrations in the deeper part of the cage may be caused by net deformations as previously seen within the present cages with typically the net wall being forced to the side and reducing the volume, predominantly at greater depths (e.g. Lader et al. 2008). Thus, in the deeper parts of the cage the water current may change the angle between the more or less statically positioned measure frame and the dynamic fish school.

\subsection{Practical implications}

The current finding is obviously an important consideration when attempting representative sampling of fish in sea cages, both when using measuring frames and casting net hauls from bottom and up. Considering the present distribution, the latter method may result in overrepresentation of large fish as fish positioned closer to the surface will have more time to avoid the ascending net when hauled from the cage bottom. Using cast net within the surface layer only, may however display overrepresentation of small fish.

Potentially, fish swimming deeper in the cages will get less sea lice (Huse and Holm 1993; Osland et al. 2001; Hevrøy et al. 2003; Oppedal et al. 2011a) as the infective copepodid stage of sea lice larvae is pelagic, strongly phototactic 
(Bron et al. 1993), and typically occurs in greatest abundances at shallow depths in coastal waters (Johannessen 1978; Costelloe et al. 1996, 1999; McKibben and Hay 2004). Therefore, smaller salmon near the surface may have higher sea lice abundance compared to larger salmon deeper in the cage. This needs to be accounted for during management and control of the parasite.

\subsection{Future perspectives}

The current experiment was carried out in small scale compared to industrial sea cages, and salmon group dynamics may be different in larger group sizes and cage volumes. The environmental conditions were relatively stable in the current experiment, and studies that involve environmental fluctuations and seasonal changes should resolve possible effects of environmental variables on the vertical size distribution. Moreover, similar investigation earlier in the production cycle may broaden our understanding regarding the development of different size classes and size stratification of salmon in sea cages by identifying environmental preferences compared to growth.

Size related individual differences in swimming speed may affect the radial positioning in circular schooling salmon. For instance, individuals that swim at the outer part of the school near the cage wall must swim faster to complete a round within the same time than fish swimming towards the centre, and it is thus possible that larger fish with higher swimming speed are found at the edge of the school. Further investigations involving multiple radial positions of measure frames are needed to address this question.

The number of observations per cage shows that each individual fish on average was measured more than twice. Potential individual differences in the willingness to swim through the measure frame connected to size, swimming speed, individual coping style (Øverli et al. 2002) or nutritional status cannot be sorted out from the current data, and is a subject for further investigation. The general trend of increased size with depth and minimal overlap between the weight distributions at the lower and partially the higher end of the total weight spectrum does, however, rule out the possibility that the main finding that larger fish are found deeper are an artefact caused by such effects. Studies using individual depth tags have shown great individual variation in swimming depth of caged salmon, but have not found any correlation between fish size and swimming depth (Johansson et al. 2009; Korsøen et al. 2012) which may be related to low test strength in these studies (11 tagged individuals in Johansson et al. 2009, and 26 in Korsøen et al. 2012). Moreover, the study using the largest sample (26 tagged individuals) was conducted on much smaller fish (average weight of $0.5 \mathrm{~kg}$ ) and during different environmental conditions than in the present study.

\subsection{Conclusion}

During the prevailing environmental conditions with relatively homogenous water in the main volume of the cage, size-dependent vertical distribution is evident. This observation may be ascribed to natural behavioural traits and introduces an important consideration in representative sampling within commercial cages. In future biomass estimations and sea lice counts this needs to be acknowledged.

Acknowledgements. The study has been carried out with financial support from Research Council of Norway, Project EXACTUS (199788/S40), Technologies, systems and operational procedures for high-level accuracy in biomass control in large cages. We are grateful to the staff of the Matre Aquaculture Research Station for their technical assistance and in particular research assistant Tone Vågseth, Vaki for software solutions to retain individual registrations, and the anonymous referees for comments that improved the manuscript.

\section{References}

Ang K.P., Petrell R.J., 1998, Pellet wastage, and subsurface and surface feeding behaviours associated with different feeding systems in sea cage farming of salmonids. Aquac. Eng. 18, 95-115.

Austreng E., Storebakken T., Åsgård T., 1987, Growth rate estimates for cultured Atlantic salmon and rainbow trout. Aquaculture 60, 157-160.

Bjordal Å., Juell J.E., Lindem T., Fernö A., 1993, Hydroacoustic monitoring and feeding control in cage rearing of Atlantic salmon (Salmo salar L.). In: Reinertsen H., Dahle L.A., Jørgensen L., Tvinnereim K. (eds.), Fish Farming Technology. Balkema, Rotterdam, pp. 203-208.

Bone Q., Moore R., 2008, Buoyancy. In: Bone Q., Moore R. (eds.), Biology of fishes. Taylor and Francis, New York, pp. 101-124.

Bron J.E., Sommerville C., Rae G.H., 1993, Aspects of the behaviour of copepodid larvae of the salmon louse Lepeophtheirus salmonis (Krøyer 1837). In: Boxshall G.A., Defaye G. (eds.), Pathogens of Wild and Farmed Fish: Sea Lice. Ellis Horwood, Chichester, pp. 125-142.

Costelloe M., Costelloe J., Roche N., 1996, Planktonic dispersion of larval salmon-lice, Lepeophtheirus salmonis, associated with cultured salmon, Salmo salar, in western Ireland. J. Mar. Biol. Assoc. UK 76, 141-149.

Costelloe M., Costelloe J., O’Donohoe G., Coghlan N., O'Connor B., 1999, A review of field studies on the sea louse, Lepeophtheirus salmonis Kroyer on the west coast of Ireland. Bull. Eur. Assoc. Fish Pathol. 19, 260-264.

Crawley M.J., 2007, Proportion data, in: The R Book. West Sussex, Wiley.

Cubitt K.F., Winberg S., Huntingford F.A., Kadri S., Crampton V.O., Øverli Ø., 2008, Social hierarchies, growth and brain serotonin metabolism in Atlantic salmon (Salmo salar) kept under commercial rearing conditions. Physiol. Behav. 94, 529-535.

Dempster T., Juell J.-E., Fosseidengen J.E., Fredheim A., Lader P., 2008, Behaviour and growth of Atlantic salmon (Salmo salar L.) subjected to short-term submergence in commercial scale seacages. Aquaculture 276, 103-111.

Dempster T., Korsøen Ø., Folkedal O., Juell J.-E., Oppedal F., 2009, Submergence of Atlantic salmon (Salmo salar L.) in commercial scale sea-cages: A potential short-term solution to poor surface conditions. Aquaculture 288, 254-263.

Einen O., Waagan B., Thomassen M.S., 1998, Starvation prior to slaughter in Atlantic salmon (Salmo salar). I. Effects on weight loss, body shape, slaughter- and fillet-yield, proximate and fatty acid composition. Aquaculture 166, 85-104.

Fernö A., Furevik D., Huse I., Bjordal A., 1988, A multiple approach to behaviour studies of salmon reared in marine net pens. Counc. Meet. Int. Counc. Explor. Sea CM 1-15 (1988/F15). 
Fernö A., Huse I., Juell J.-E., Bjordal A., 1995, Vertical distribution of Atlantic salmon (Salmo salar L.) in net pens - trade-off between surface light avoidance and food attraction. Aquaculture 132, 285-296.

Hevrøy E.M., Boxaspen K., Oppedal F., Taranger G.L., Holm J.C., 2003, The effect of artificial light treatment and depth on the infestation of the sea louse Lepeophtheirus salmonis on Atlantic salmon (Salmo salar L.) culture. Aquaculture 220, 1-14.

Hoare D.J., Krause J., Peuhkuri N., Godin J.G.J., 2000, Body size and shoaling in fish. J. Fish Biol. 57, 1351-1366.

Huse I., Holm J.C., 1993, Vertical distribution of Atlantic salmon (Salmo salar) as a function of illumination. J. Fish Biol. 43, 147156.

Johannessen A., 1978, Early stages of Lepeophtheirus salmonis (Copepoda, Caligidae). Sarsia 63, 169-176.

Johansson D., Ruohonen K., Kiessling A., Oppedal F., Stiansen J.E., Kelly M., Juell J.-E., 2006, Effect of environmental factors on swimming depth preferences of Atlantic salmon (Salmo salar L.) and temporal and spatial variations in oxygen levels in sea cages at a fjord site. Aquaculture 254, 594-605.

Johansson D., Juell J.-E., Oppedal F., Stiansen J.E., Ruohonen K., 2007, The influence of the pycnocline and cage resistance on current flow, oxygen flux and swimming behaviour of Atlantic salmon (Salmo salar L.) in production cages. Aquaculture 265, 271-287.

Johansson D., Ruohonen K., Juell J.-E., Oppedal F., 2009, Swimming depth and thermal history of individual Atlantic salmon (Salmo salar L.) in production cages under different ambient temperature conditions. Aquaculture 290, 296-303.

Juell J.-E., 1995, The behaviour of Atlantic salmon in relation to efficient cage-rearing. Rev. Fish Biol. Fish. 5, 320-335.

Juell J.-E., Westerberg H., 1993, An ultrasonic telemetric system for automatic positioning of individual fish used to track Atlantic salmon (Salmo salar L.) in a sea cage. Aquac. Eng. 12, 1-18.

Juell J.-E., Fernö A., Furevik D., Huse I., 1994, Influence of hunger level and food availability on the spatial distribution of Atlantic salmon, Salmo salar L., in sea cages. Aquac. Fish. Manage. 25, 439-451.

Korsøen Ø.J., Dempster T., Fjelldal P.G., Oppedal F., Kristiansen T.S., 2009, Long-term culture of Atlantic salmon (Salmo salar L.) in submerged cages during winter affects behaviour, growth and condition. Aquaculture 296, 373-381.

Korsøen Ø.J., Dempster T., Fjelldal P.G., Oppedal F., Kristiansen T.S., 2012, Individual variation in swimming depth and growth in Atlantic salmon (Salmo salar L.) subjected to submergence in sea-cages. Aquaculture 334, 142-151.

Krause J., 1994, The influence of food competition and predation risk on size-assortative shoaling in juvenile chub (Leuciscus cephalus). Ethology 96, 105-116.

Lader P., Dempster T., Fredheim A., Jensen O., 2008, Current induced net deformations in full-scale sea-cages for Atlantic salmon (Salmo salar). Aquac. Eng. 38, 52-65.
Lekang O.I., 2007, Aquaculture Engineering. Blackwell, Oxford, UK, pp. 277-280.

McKibben M.A., Hay D.W., 2004, Distributions of planktonic sea lice larvae Lepeophtheirus salmonis in the inter-tidal zone in Loch Torridon, Western Scotland in relation to salmon farm production cycles. Aquac. Res. 35, 742-750.

Nordgarden U., Oppedal F., Taranger G.L., Hemre G.I., Hansen T., 2003, Seasonally changing metabolism in Atlantic salmon (Salmo salar L.). I. Growth and feed conversion ratio. Aquac. Nutr. 9, 287-293.

Oppedal F., Juell J.-E., Taranger G.L., Hansen T., 2001, Artificial light and season affects vertical distribution and swimming behaviour of post-smolt Atlantic salmon in sea cages. J. Fish Biol. 58, 15701584.

Oppedal F., Juell J.-E., Johansson D., 2007, Thermo- and photoregulatory swimming behaviour of caged Atlantic salmon: implications for photoperiod management and fish welfare. Aquaculture 265, 70-81.

Oppedal F., Dempster T., Stien L.H., 2011a, Environmental drivers of Atlantic salmon behaviour in sea-cages: a review. Aquaculture $311,1-18$.

Oppedal F., Vågseth T., Dempster T., Juell J.-E., Johansson D., 2011b, Fluctuating sea-cage environments modify the effects of stocking densities on production and welfare parameters of Atlantic salmon (Salmo salar L.). Aquaculture 315, 361-368.

Osland H., Sandvik J.I., Holm J., Heuch P.-A., Bakke S., 2001, Studie av lakseluspåslag og tilvekst hos Atlantisk laks (Salmo salar) i nedsenkede merder. HSF-report, R-NR 4/01, 22 p. (In Norwegian).

Øverli Ø., Sørensen C., Pulman K.G.T., Pottinger T.G., Korzan W., Summers C.H., Nilsson G.E., 2007, Evolutionary background for stress-coping styles: Relationships between physiological, behavioral, and cognitive traits in non-mammalian vertebrates. Neurosci. Biobehav. Rev. 31, 396-412.

Pitcher T.J., Parrish J.K., 1993, Functions of shoaling behaviour in teleosts. In: Pitcher T.J. (ed.), Behaviour of teleost fishes. Chapman \& Hall, London, pp. 363-439.

Pitcher T.J., Magurran A.E., Edwards J.I., 1985, Schooling mackerel and herring choose neighbors of similar size. Mar. Biol. 86, 319322.

Sette O.E., 1950, Biology of the Atlantic mackerel (Scomber scombrus) of North America. Part 2. Migrations and habits. Fish. Bull. Nat. Mar. Fish. Serv. US 51, 251-358.

Solberg C., Saugen E., Swenson L.-P., Bruun L., Isaksson T., 2003, Determination of fat in live farmed Atlantic salmon using noninvasive NIR techniques. J. Sci. Food Agric. 83, 692-696.

Stephen C., Ribble C.S., 1995, An evaluation of surface moribund salmon as indicators of seapen disease status. Aquaculture 133, $1-8$.

Theodorakis C.W., 1989, Size segregation and the effects of oddity on predation risk in minnow schools. Anim. Behav. 38, 496-502. 